Supporting Information

\title{
Acid-induced Self-catalyzing Platform Based on Dextran Coated Copper Peroxide Nanoaggregates for Biofilm Treatment
}

\author{
Min Li ${ }^{\text {a }}$ Xi Lan ${ }^{\mathrm{a}}$, Ximei Han ${ }^{\mathrm{a}}$, Shuo Shi ${ }^{\mathrm{a}}$, Hao Sun ${ }^{\mathrm{a}}$, Yi Kanga ${ }^{\mathrm{a}}$, Jie Dan ${ }^{\mathrm{a}}$, Jing Sun ${ }^{\mathrm{b}}$, Wentao \\ Zhang, $^{\mathrm{a}, *}$, Jianlong Wang ${ }^{\mathrm{a}, *}$
}

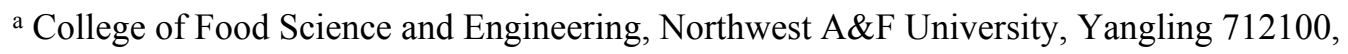

Shaanxi, China

${ }^{\mathrm{b}}$ Qinghai Key Laboratory of Qinghai-Tibet Plateau Biological Resources, Northwest Institute of Plateau Biology, Chinese Academy of Sciences, Xining 810008, Qinghai, China

*Corresponding author.

E-mail: zhangwt@nwsuaf.edu.cn

wanglong79@,nwsuaf.edu.cn

Fax: +86 29-8709-2275;

Tel: +86 29-8709-2275 


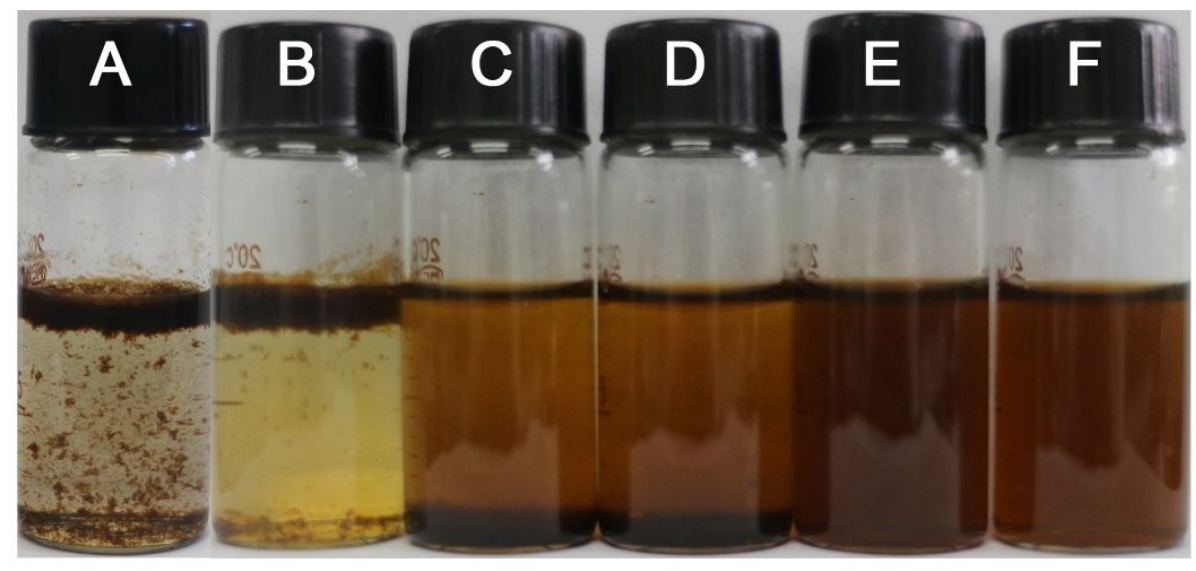

Figure S1. Photograph of DCPNAs synthesized with dextran at different concentration of (A) $0 \mathrm{mg} \mathrm{mL}^{-1}$, (B) $10 \mathrm{mg} \mathrm{mL}^{-1}$, (C) $20 \mathrm{mg} \mathrm{mL}^{-1}$, (D) $30 \mathrm{mg} \mathrm{mL}^{-1}$, (E) $40 \mathrm{mg} \mathrm{mL}^{-1}$, (F) $50 \mathrm{mg} \mathrm{mL}^{-1}$. 


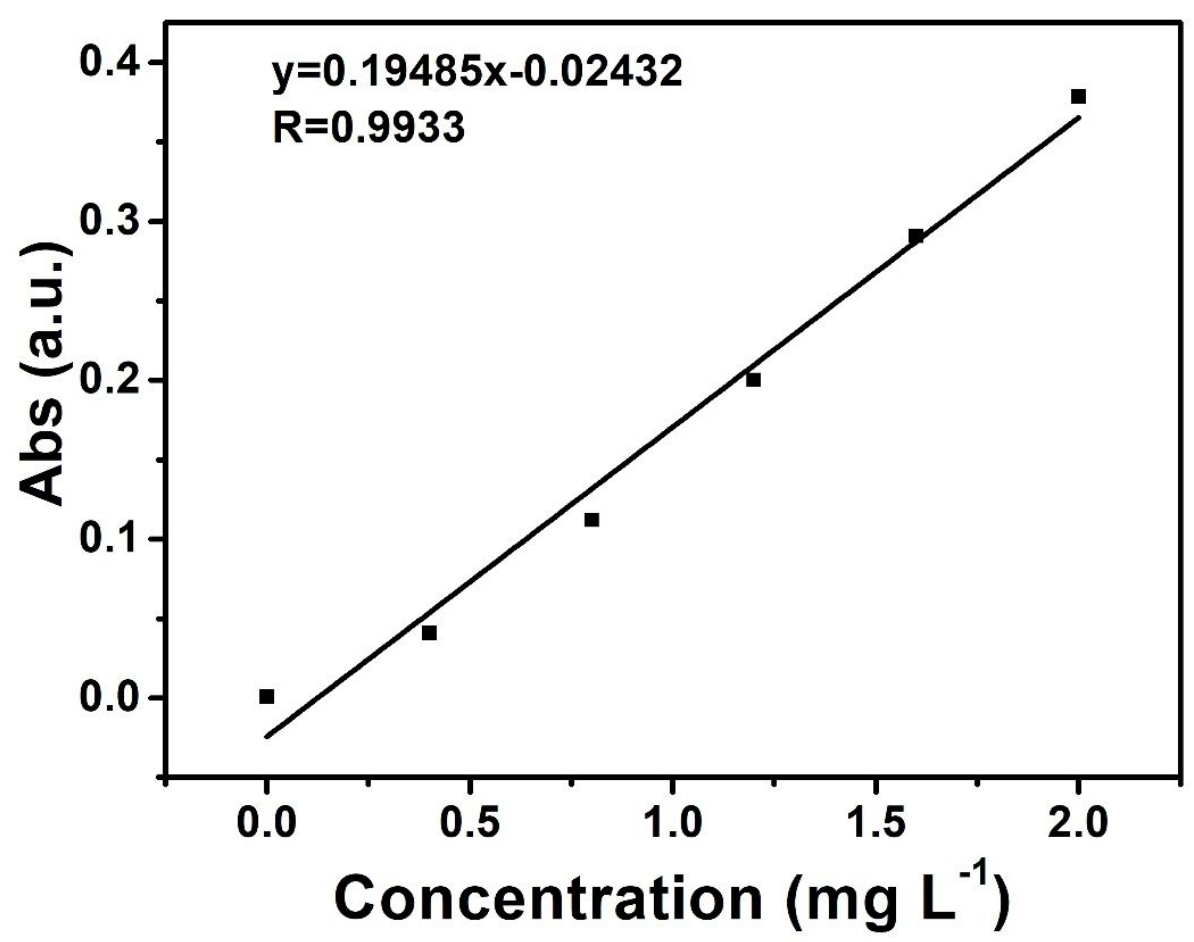

Figure S2. Calibration curve of copper element detection using a flame atomic absorption spectrometer (FAAS 


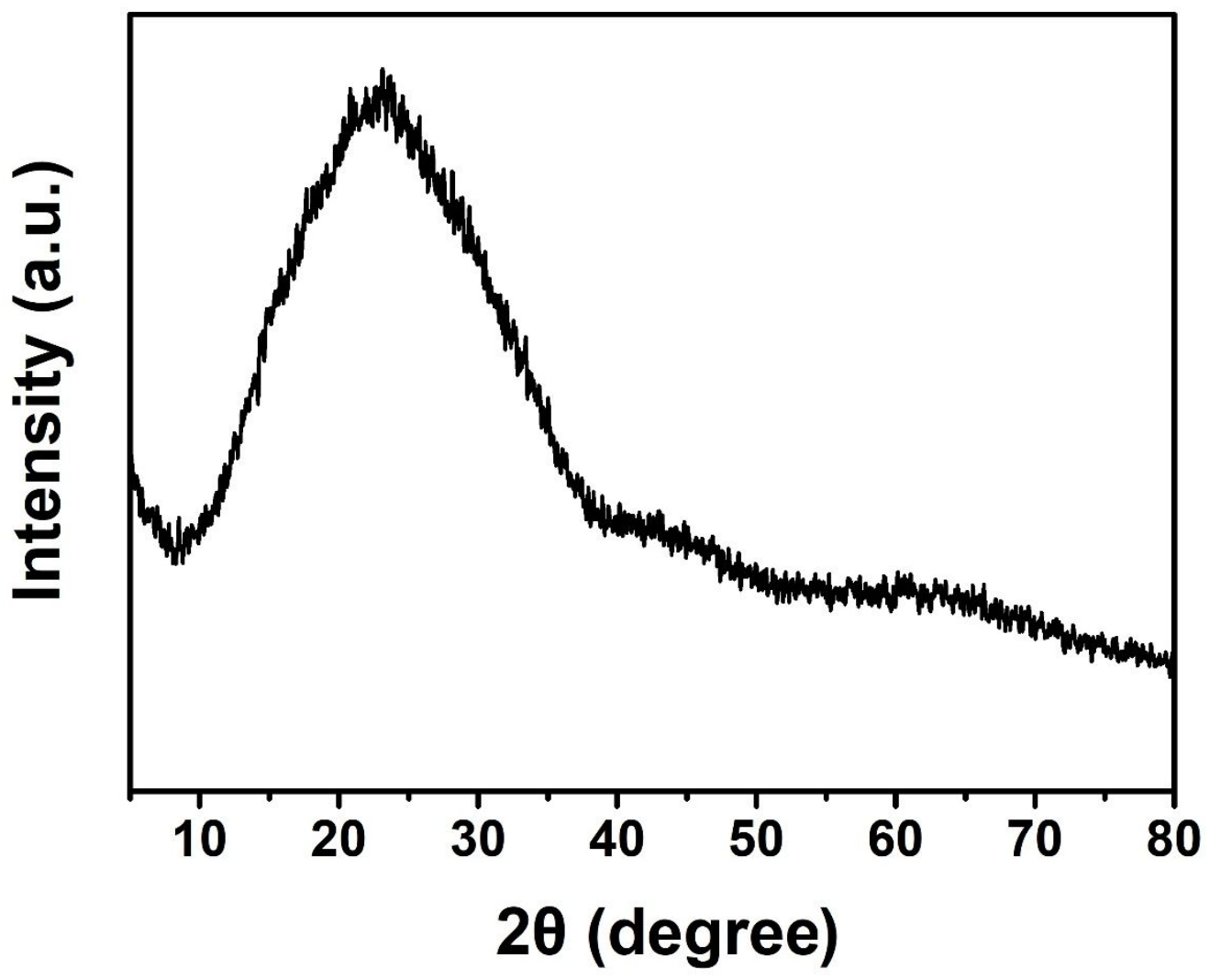

Figure S3. XRD patterns for dextran. 


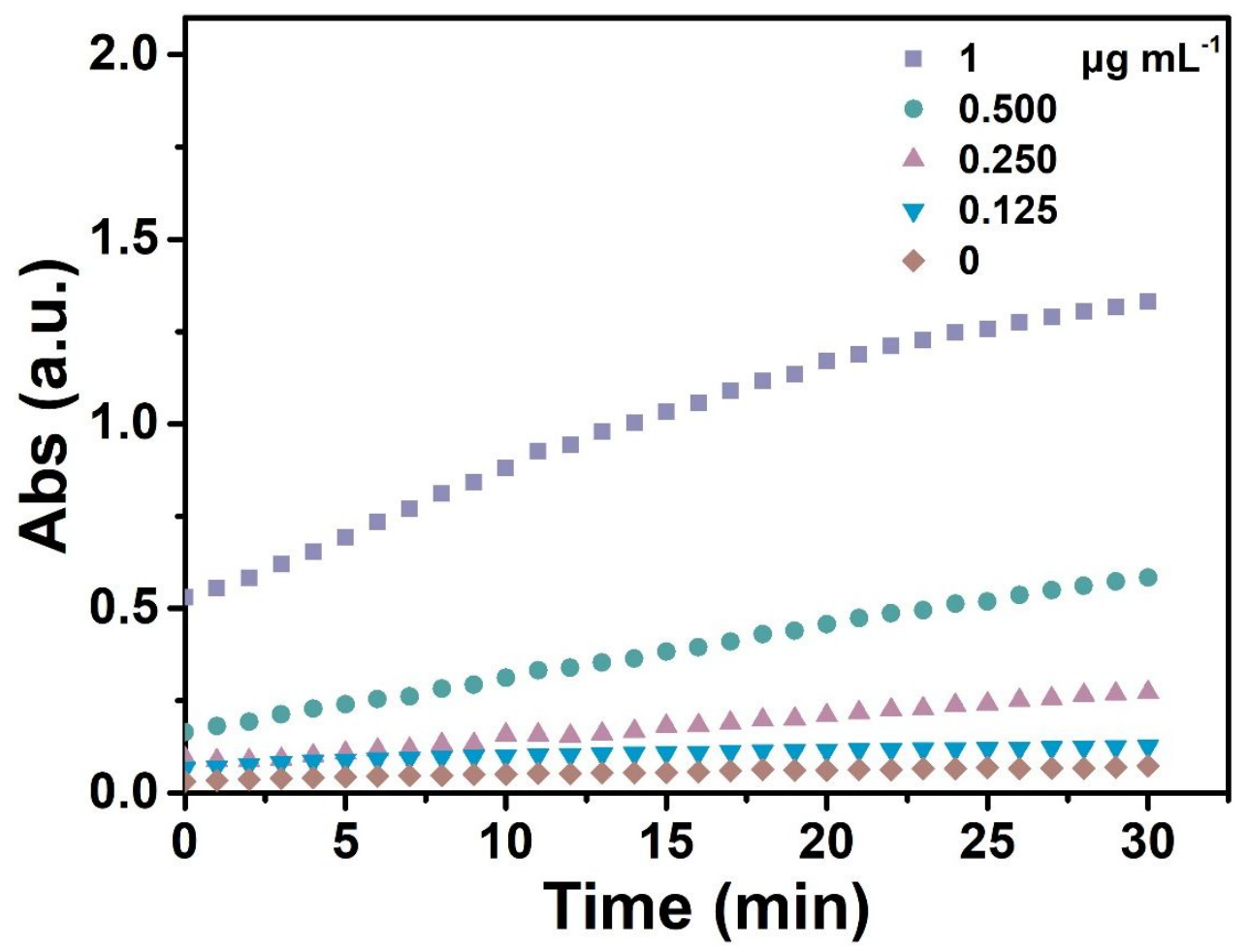

Figure S4. Detection of the catalytic performance of DCPNAs with different concentration at per minute within 30 minutes via TMB assay. 


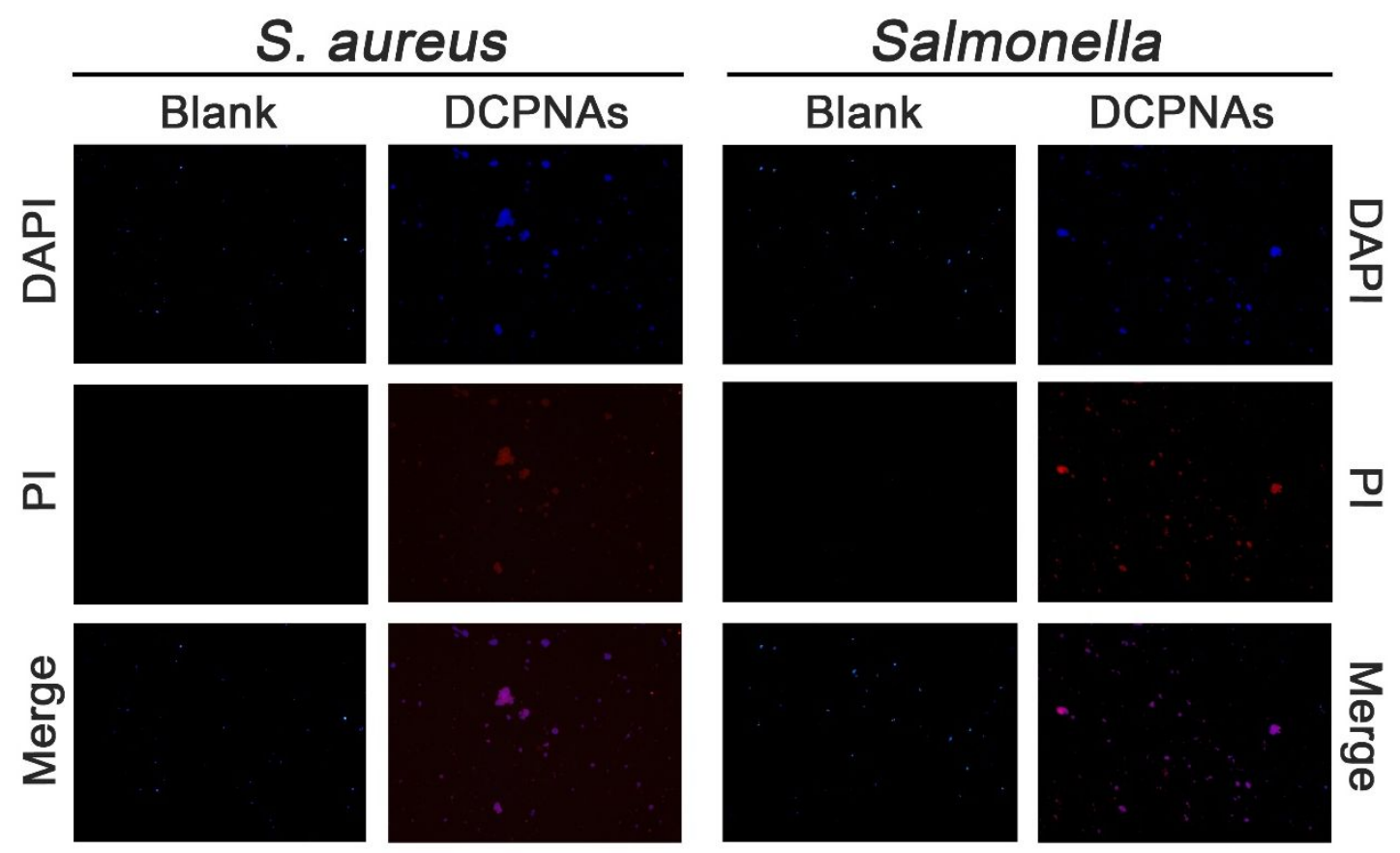

Figure S5. Representative fluorescent images of S. aureus and Salmonella treated with and without DCPNAs at pH 5.6. 

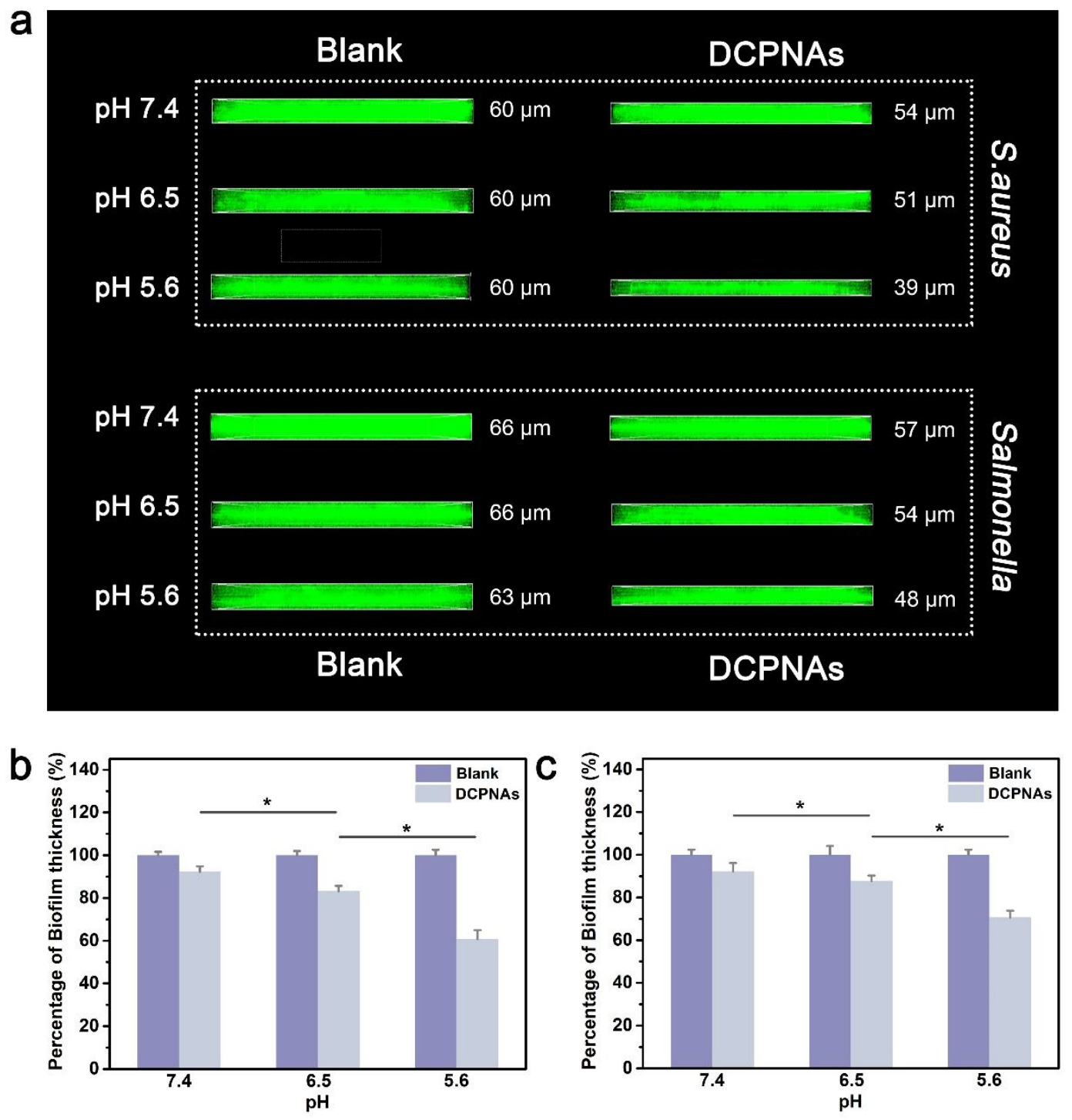

Figure S6. (a) Confocal laser scanning microscopy (CLSM) images of the thickness of biofilms after the inhibition of DDCPNAs at different $\mathrm{pH}$ values. Biofilm thickness of (b) S. aureus and (c) Salmonella treated with and without DCPNAs at different $\mathrm{pH}$ values $(\mathrm{n}=3, * \mathrm{P}<0.05)$. 


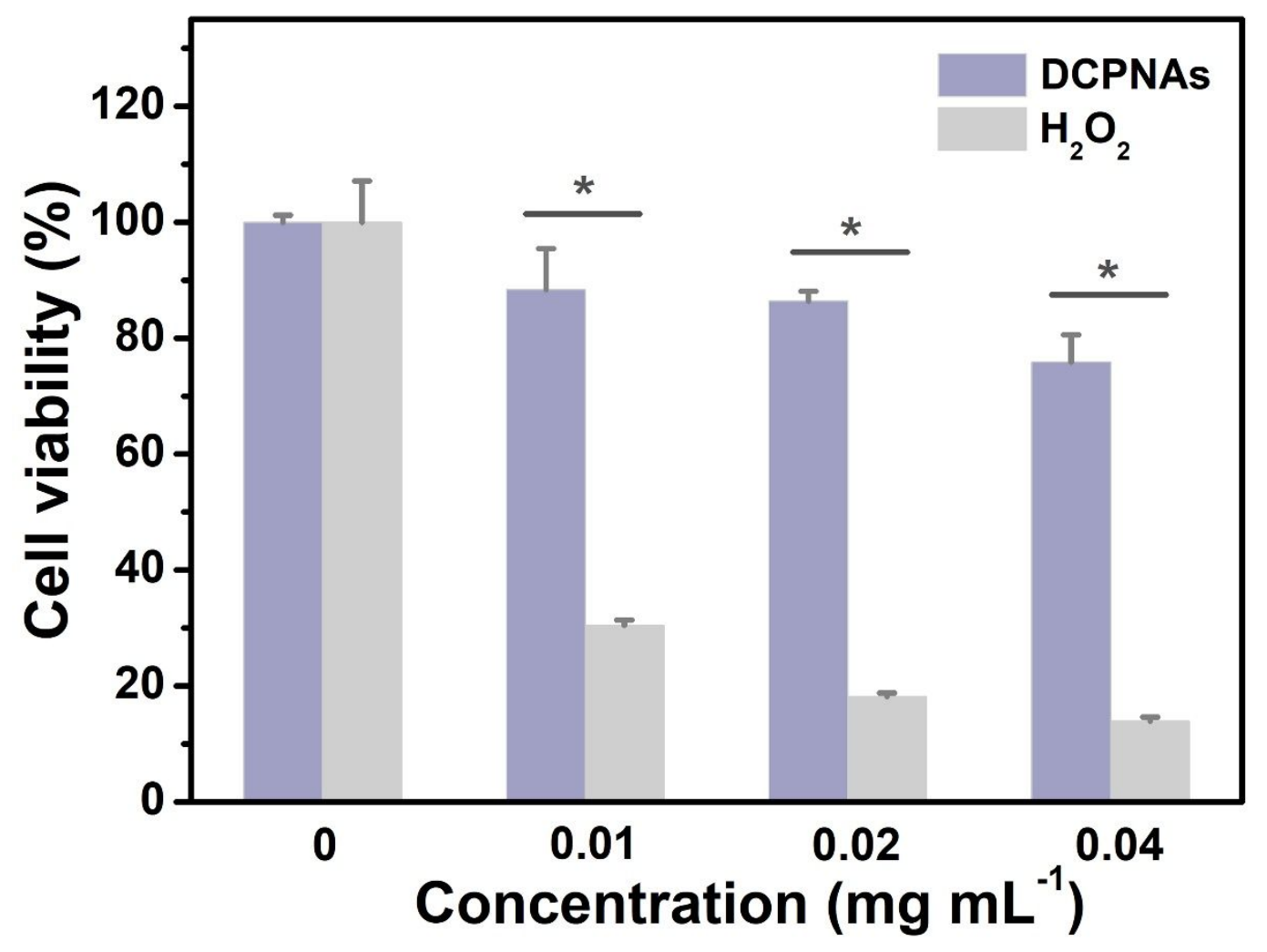

Figure S7. Cell viability percentages after the cells were exposed to DCPNAs and $\mathrm{H}_{2} \mathrm{O}_{2}$ at different concentrations for $12 \mathrm{~h}(\mathrm{n}=3, * \mathrm{P}<0.05)$. 